\title{
Assessment of the students' achievement of learning outcomes of radiological sciences program, Najran University experiment
}

\author{
Soheir E. Mohamed* \\ Radiological Sciences Department, Applied Medical Sciences College, Najran University, KSA.
}

GSC Biological and Pharmaceutical Sciences, 2021, 14(01), 129-136

Publication history: Received on 10 January 2021; revised on 17 January 2021; accepted on 19 January 2021

Article DOI: https://doi.org/10.30574/gscbps.2021.14.1.0020

\begin{abstract}
The present study was conducted to evaluate the achievement of undergraduate radiological sciences students of PLOs by the applied method in Radiological sciences, Najran University. The assessment of the program learning outcomes in department of radiological sciences, Najran University was conducted by direct and indirect methods and analysis the results of students' achievement. The study was applied on 21 graduating students, batch of academic year 2019-2020 by applying Najran University model. Direct measurement was applied by linking of each PLO to exams questions on quizzes, midterm exams, final exams, project work and presentation. Indirect method was implemented based on surveys; exist, alumni and employers' surveys.

Najran University model is able to measure the achievement of PLOs and it supported by an indirect assessment method. The radiological sciences program highlights on the student outcomes for the graduate for continuous quality of the curriculum and teaching and learning process in future.
\end{abstract}

Keywords: Program Learning Outcomes; Direct and indirect methods; Assessment; students' achievement; Radiological sciences.

\section{Introduction}

Higher education institutions have acknowledged the importance of assessing student learning outcomes. The results of these assessments can be used in developing methods for ensuring positive learning outcomes [1].

Outcomes based education (OBE) is as an educational process which is based on achievement the outcomes for individual student learning [2]. It involves revising of the curriculum and assessment methods to reflect the achievement of high order learning [3]. All curriculum and teaching decisions are made based on how best to facilitate the desired final outcome [4]-[5]. The unambiguous outcome is used to plan the curriculum, monitor its implementation, evaluate it and assess student's achievement (6). In outcomes-based education, the learning system should align the teaching methods and the assessment, and CLOs are achieved [7]-[9].

Assessment is one or more processes that identify, collect, and prepare data to examine the achievement of program outcomes and its educational objectives [10].

Student learning outcomes assessment is conducted by colleges and universities at the undergraduate and graduate levels for academic departments to determine whether programs cover the material stated in their learning goals, whether students are learning the material, and the impact on student retention, graduation, post-graduation outcomes,

\footnotetext{
${ }^{*}$ Corresponding author: Soheir E. Mohamed

Radiological Sciences Department, Applied Medical Sciences College, Najran University, KSA.
} 
and institutional accreditation, with the aim of providing faculty with data that can be used to help programs evolve or improve [11].

The calculating of PLOs is conducting by using direct and indirect assessment methods, and using these collected results as a catalyst for change and improvements, such as revising curricula and courses structures, improving the learning activities and enhancing the faculty teaching competence.

The aim of the present study is focusing on the model of assessment the student's achievement of PLOs radiological sciences program at Najran University.

The assessment is a process of collect data to evaluate the attainment of PLOs. Different types of assessment are used to measure PLOs and CLOs as direct and indirect methods [12]-[15]. A novel method evaluates the attainment level for course outcomes as well as program outcomes could be proposed by Sudheer et al [16]. The result of PLOs measurements is used to promote the quality of the teaching and learning processes in the program.

The courses are mapped to PLOs by examining individual learning outcomes of each course. The students' achievement of CLOs of each course are assessed. Every PLO is evaluated individually based on data collected from courses' exams results, faculty, students, alumni, internship, and employers to measure its performance level [14],[17]. Based on recent proposed suggestion, the study on the impact of different assessment methods for radiological sciences students at Najran University are required in order to ensure the quality of students' achievement and their evaluation feedback [18].

\section{Methodology}

Program of radiological sciences one of the undergraduate programs in applied medical sciences college at Najran University, the program provides B.Sc. degree in radiological sciences, which requires the completion of $142 \mathrm{credit}$ hours. There are (11) LOs of the specified program, they cover the three different domains (knowledge, skills and competence). Learning outcomes statements of the radiological sciences program are arranged in the Table 1.

Table 1 PLOs statements

\begin{tabular}{|l|l|}
\hline PLOs & Statement \\
\hline PL01 & Explain the concepts of basic principles of medical sciences, physics and the associated applications. \\
\hline PL02 & Describe the methods of different medical imaging procedures. \\
\hline PL03 & $\begin{array}{l}\text { Practice basics and medical sciences applications and imaging procedures in medical laboratories with } \\
\text { the optimal patient care and protection. }\end{array}$ \\
\hline PL04 & Operate effectively and safely the different medical imaging modalities. \\
\hline PL05 & $\begin{array}{l}\text { Evaluate the medical images of different modalities and differentiate between the normal and abnormal } \\
\text { appearance. }\end{array}$ \\
\hline PL06 & Manage the operation of different medical imaging modalities effectively and accurately. \\
\hline PL07 & Acquire an interpretable high-quality image utilizing different imaging modalities. \\
\hline PL08 & $\begin{array}{l}\text { Carry out the optimal imaging examinations dependent on the assessment of patient conditions and } \\
\text { safety requirements with ethical and legal manners. }\end{array}$ \\
\hline PL09 & Demonstrate basics management and research skills. \\
\hline PL010 & Communicate effectively with patient, colleagues and other health professionals. \\
\hline PL011 & Demonstrate teamwork and inter-professional collaboration. \\
\hline
\end{tabular}

The direct methods to assess the students' achievement of LOs of the radiological sciences program are tabulated in the Table 2 . 
Table 2 Direct assessment methods per each PLO

\begin{tabular}{|l|l|l|l|l|l|l|l|l|l|l|l|}
\hline Assessment methods & PL01 & PL02 & PLO3 & PL04 & PLO5 & PLO6 & PL07 & PL08 & PL09 & PL010 & PL011 \\
\hline Midterm written exam & $\sqrt{ }$ & $\sqrt{ }$ & & & & & & & & & \\
\hline Final written exam & $\sqrt{ }$ & $\sqrt{ }$ & & & & & & & & & \\
\hline Quizzes & $\sqrt{ }$ & $\sqrt{ }$ & & & & & & & & & \\
\hline Assignments & $\sqrt{ }$ & $\sqrt{ }$ & $\sqrt{ }$ & $\sqrt{ }$ & $\sqrt{ }$ & & & & $\sqrt{ }$ & & \\
\hline Midterm practical exam & & & $\sqrt{ }$ & $\sqrt{ }$ & $\sqrt{ }$ & $\sqrt{ }$ & $\sqrt{ }$ & $\sqrt{ }$ & & & \\
\hline Final practical exam & & & $\sqrt{ }$ & $\sqrt{ }$ & $\sqrt{ }$ & $\sqrt{ }$ & $\sqrt{ }$ & $\sqrt{ }$ & & & \\
\hline Log book & & & & & & $\sqrt{ }$ & $\sqrt{ }$ & $\sqrt{ }$ & & & \\
\hline $\begin{array}{l}\text { Performance } \\
\text { evaluation }\end{array}$ & & & & & & $\sqrt{ }$ & $\sqrt{ }$ & $\sqrt{ }$ & & & \\
\hline Project work & & & & & & & & & $\sqrt{ }$ & $\sqrt{ }$ & $\sqrt{ }$ \\
\hline Presentation & & & & & & & & & $\sqrt{ }$ & $\sqrt{ }$ & $\sqrt{ }$ \\
\hline
\end{tabular}

PLOs courses map with their relative weights are prepared due to the key faculty staff assessment and designed in in Excel sheet as shown in Table 3.

Table 3 PLOs and courses map with relative weights

\begin{tabular}{|c|c|c|c|c|c|c|c|c|c|c|c|}
\hline Course / PLOs & PLO1 & PLO2 & PLO3 & PLO4 & PLO5 & PL06 & PLO7 & PL08 & PLO9 & PL010 & PL011 \\
\hline Physiology & $14 \%$ & & $3 \%$ & & $6 \%$ & & & & & & $5 \%$ \\
\hline Histology & $14 \%$ & & $3 \%$ & & & $6 \%$ & & & & & $5 \%$ \\
\hline Anatomy & $14 \%$ & & & & $6 \%$ & & & & & & $5 \%$ \\
\hline Pathology & $16 \%$ & & $4 \%$ & & & $6 \%$ & & & & & $5 \%$ \\
\hline Radiation Physics & $14 \%$ & & $4 \%$ & & & $6 \%$ & & & & & $5 \%$ \\
\hline G. Investigations & & $4 \%$ & $4 \%$ & $6 \%$ & & $6 \%$ & $5 \%$ & & $11 \%$ & & $5 \%$ \\
\hline Patient Care & & $4 \%$ & $3 \%$ & & & $6 \%$ & & & & $8 \%$ & \\
\hline Ultrasound Physics & & $4 \%$ & $4 \%$ & & & $6 \%$ & $5 \%$ & & & & \\
\hline Rad. Protection & $14 \%$ & & $3 \%$ & & & $6 \%$ & & & & & $5 \%$ \\
\hline Practical Tr. (1) & & $4 \%$ & $4 \%$ & $6 \%$ & $6 \%$ & & $5 \%$ & $6 \%$ & $11 \%$ & $8 \%$ & $5 \%$ \\
\hline S. Investigations & & $4 \%$ & $4 \%$ & $6 \%$ & $6 \%$ & & $5 \%$ & & & & $5 \%$ \\
\hline Cross S. Anatomy & $14 \%$ & & & & $6 \%$ & & & & & $8 \%$ & \\
\hline Nuclear M. Physics & & $4 \%$ & $4 \%$ & & & $6 \%$ & & & & $8 \%$ & \\
\hline US. Technique & & $4 \%$ & $4 \%$ & $6 \%$ & & $6 \%$ & $5 \%$ & $6 \%$ & & & $5 \%$ \\
\hline Fluoroscopy & & $4 \%$ & $4 \%$ & $6 \%$ & $7 \%$ & & $5 \%$ & $6 \%$ & & & \\
\hline Advanced Tech. & & $4 \%$ & $4 \%$ & $6 \%$ & & $6 \%$ & $5 \%$ & $6 \%$ & & & \\
\hline Practical Tr. (2) & & $4 \%$ & $4 \%$ & $6 \%$ & $7 \%$ & & $5 \%$ & $6 \%$ & $11 \%$ & $8 \%$ & $5 \%$ \\
\hline $\mathrm{CT}$ & & $4 \%$ & $4 \%$ & $6 \%$ & $7 \%$ & & $6 \%$ & $7 \%$ & & & $5 \%$ \\
\hline Practical Tr. (3) & & $4 \%$ & $4 \%$ & $6 \%$ & $7 \%$ & & $6 \%$ & $7 \%$ & $11 \%$ & $8 \%$ & $5 \%$ \\
\hline Practical Tr. (4) & & $4 \%$ & $4 \%$ & $6 \%$ & $7 \%$ & & $6 \%$ & $7 \%$ & $11 \%$ & $8 \%$ & $5 \%$ \\
\hline Adv. Equipment & & $4 \%$ & $4 \%$ & $6 \%$ & & $8 \%$ & $6 \%$ & $7 \%$ & & & \\
\hline Emergency & & $4 \%$ & $4 \%$ & $6 \%$ & $7 \%$ & & $6 \%$ & $7 \%$ & $11 \%$ & & $5 \%$ \\
\hline Nuclear Medicine & & $4 \%$ & $4 \%$ & & & $8 \%$ & & & & $8 \%$ & \\
\hline Film Reading & & $4 \%$ & & & $7 \%$ & & & $7 \%$ & & & \\
\hline Practical Tr. (5) & & $4 \%$ & $4 \%$ & $7 \%$ & $7 \%$ & & $6 \%$ & $7 \%$ & $11 \%$ & $8 \%$ & $5 \%$ \\
\hline Practical Tr. (6) & & $4 \%$ & $4 \%$ & $7 \%$ & $7 \%$ & & $6 \%$ & $7 \%$ & $11 \%$ & $8 \%$ & $5 \%$ \\
\hline MRI & & $6 \%$ & $4 \%$ & $7 \%$ & & $8 \%$ & $6 \%$ & $7 \%$ & & & $5 \%$ \\
\hline Practical Tr. (7) & & $6 \%$ & $4 \%$ & $7 \%$ & $7 \%$ & & $6 \%$ & $7 \%$ & $12 \%$ & $10 \%$ & $5 \%$ \\
\hline Radiotherapy & & $6 \%$ & $4 \%$ & & & $8 \%$ & $6 \%$ & & & & \\
\hline Project Work & & $6 \%$ & & & & $8 \%$ & & & & $10 \%$ & $5 \%$ \\
\hline
\end{tabular}


Firstly, the obtained students' marks for each CO assessment are entered in the designed Excel sheet model. Radiation physics course is presented as example, where its $\mathrm{CO} 1$ and $\mathrm{CO} 2$ were assessed by midterm written exam out of 20 marks. And the distribution of the exam marks for CO1 and CO2 of Radiation physics course is 8 and 12 marks respectively.

The individual student's achievement score per CO1 and CO2 according to the student performance result in the written midterm exam are entered in the designed Excel sheet model as shown in Table 4 (a).

Table 4 (a) Students marks in each CO

\begin{tabular}{|l|l|l|l|l|}
\hline Sn. & Name & Total/20 & CO1 & CO2 \\
\hline 1 & student 1 & 12 & 5 & 7 \\
\hline 2 & student 2 & 12 & 4 & 8 \\
\hline 3 & student 3 & 17 & 6.2 & 10.8 \\
\hline 4 & student 4 & 18 & 6 & 12 \\
\hline 5 & student 5 & 13 & 4 & 9 \\
\hline 6 & student 6 & 11 & 5 & 6 \\
\hline 7 & student 7 & 14 & 6 & 8 \\
\hline 8 & student 8 & 12 & 6 & 6 \\
\hline 9 & student 9 & 16 & 6 & 10 \\
\hline 10 & student 10 & 10 & 5 & 5 \\
\hline 11 & student 11 & 18 & 8 & 10 \\
\hline 12 & student 12 & 16 & 5 & 11 \\
\hline 13 & student 13 & 14 & 4 & 10 \\
\hline 14 & student 14 & 15 & 6 & 9 \\
\hline 15 & student 15 & 17 & 8 & 9 \\
\hline
\end{tabular}

Secondly, the mark of the individual student per each CO is converted into percentage, where the percentages of CO1 and $\mathrm{CO} 2$ of Radiation physics course for the written midterm exam are divided to $40 \%$ and $60 \%$ respectively as shown in Table 4 (b).

Table 4 (b) Students score percentage in each CO

\begin{tabular}{|l|l|l|l|l|}
\hline Sn. & Name & \% & CO1 & CO2 \\
\hline 1 & student 1 & 60 & 62.5 & 58 \\
\hline 2 & student 2 & 60 & 50 & 67 \\
\hline 3 & student 3 & 85 & 77.5 & 90 \\
\hline 4 & student 4 & 90 & 75 & 100 \\
\hline 5 & student 5 & 65 & 50 & 75 \\
\hline 6 & student 6 & 55 & 62.5 & 50 \\
\hline 7 & student 7 & 70 & 75 & 67 \\
\hline 8 & student 8 & 60 & 75 & 50 \\
\hline 9 & student 9 & 80 & 75 & 83 \\
\hline 10 & student 10 & 50 & 62.5 & 42 \\
\hline 11 & student 11 & 90 & 100 & 83 \\
\hline 12 & student 12 & 80 & 62.5 & 92 \\
\hline 13 & student 13 & 70 & 50 & 83 \\
\hline 14 & student 14 & 75 & 75 & 75 \\
\hline 15 & student 15 & 85 & 100 & 75 \\
\hline
\end{tabular}


An overall assessment report of COs is extracted from the designed Excel sheet, where the total number of the students who completed the course and also the percentage of the students achieved the target per each CO are obtained in Excel format as shown in Table 5 .

Table 5 Model of extracted data report from designed Excel sheet for each course

\begin{tabular}{|c|c|c|c|c|c|c|}
\hline \multirow[t]{2}{*}{ COs Results } & \multicolumn{2}{|c|}{ Knowledge } & \multicolumn{2}{|c|}{ Skills } & \multicolumn{2}{|c|}{ Competence } \\
\hline & Co1 & $\mathrm{CO2}$ & $\mathrm{CO3}$ & CO4 & CO5 & C06 \\
\hline Total no. of students completed the course & & & & & & \\
\hline Percentage of students achieved the target & & & & & & \\
\hline
\end{tabular}

Finally, the result of assessment of each PLO is obtained by collected the assessment of COs for the related courses with the PLO. Where $100 \%$ of the students are expected to achieve $\geq 70 \%$.

In other hand, the indirect assessment methods of PLOs were carried out based on of surveys include exit survey, alumni survey and employers' surveys. Questionnaires were designed based on 5-point Likert scale, and the collected results from these questionnaires were analyzed. The cycle of indirect assessment methods is annually, and their KPIs equal $80 \%$ are shown in Table 6.

Table 6 Indirect assessment methods cycle.

\begin{tabular}{|l|l|l|}
\hline Indirect assessment methods & Frequency & Target \\
\hline Exit survey & Annually & $80 \%$ \\
\hline Alumni survey & Annually & $80 \%$ \\
\hline Employers surveys & Annually & $80 \%$ \\
\hline
\end{tabular}

The obtained results of the direct and indirect assessment methods of PLOs are compared and analyzed.

\section{Results and discussion}

The assessment of the students' achievement of PLOs were applied on the radiological sciences graduating students' batch of 2019-2020 (21 students). The results of the achievement of PLOs by using the direct methods for every student are shown in Table 7.

Table 7 Individual student achievement of PLOs

\begin{tabular}{|l|l|l|l|l|l|l|l|l|l|l|l|}
\hline Student ID & PLO1 & PLO2 & PLO3 & PLO4 & PLO5 & PLO6 & PLO7 & PLO8 & PL09 & PL010 & PL011 \\
\hline ID1 & 74 & 73 & 77 & 79 & 84 & 75 & 79 & 76 & 75 & 79 & 81 \\
\hline ID2 & 73 & 70 & 77.5 & 78 & 79 & 74 & 75 & 71.5 & 73 & 77.5 & 81 \\
\hline ID3 & 78 & 71 & 77 & 77 & 80 & 77 & 77 & 74.5 & 75 & 73.5 & 80 \\
\hline ID4 & 71 & 70 & 75 & 76 & 77.5 & 74 & 76 & 77.5 & 73.5 & 74 & 80.5 \\
\hline ID5 & 72 & 72 & 77 & 79 & 80 & 80 & 77 & 73 & 73 & 78 & 81.5 \\
\hline ID6 & 70 & 72 & 77 & 78 & 77 & $68.5^{*}$ & 78 & 71 & 73 & 72.5 & 81 \\
\hline ID7 & 73 & 75 & 75 & 75 & 74 & 84 & 78 & $68.5^{*}$ & 78 & 70.5 & 78 \\
\hline ID8 & 72 & 73 & 72 & 71.5 & 70.5 & 83 & 77 & 70.5 & 77.5 & 73 & 77 \\
\hline ID9 & 70 & 74 & 73.5 & 74 & 72 & 80 & 77.5 & 71.5 & 77 & 74 & 76 \\
\hline
\end{tabular}




\begin{tabular}{|l|l|l|l|l|l|l|l|l|l|l|l|}
\hline ID10 & 70 & 75 & 75 & 75 & 73 & 82 & 78 & 72 & 78 & 75.5 & 76.5 \\
\hline ID11 & $65^{*}$ & 74.5 & 74 & 74 & 73 & 73 & 77 & $69^{*}$ & 77 & 73 & 75 \\
\hline ID12 & 71 & 74 & 74.5 & 74 & 73.5 & 73 & 76 & $67.5^{*}$ & 76 & 72 & 75 \\
\hline ID13 & 73 & 74 & 74 & 74.5 & 73 & 75 & 77 & 74 & 77 & 74 & 77 \\
\hline ID14 & $64^{*}$ & 74.5 & 74 & 74 & 73.5 & 68.5 & $69^{*}$ & $64.5^{*}$ & 75.5 & 71 & 75 \\
\hline ID15 & $65^{*}$ & 71 & 71 & 71.5 & 73 & 73 & 75 & 75 & 75 & 72.5 & 75.5 \\
\hline ID16 & 72 & 73.5 & 73 & 73 & 67.5 & $69^{*}$ & $67.5^{*}$ & 71.5 & 78 & 73 & 78 \\
\hline ID17 & $69^{*}$ & 74 & 74.5 & 74 & 73.5 & 73 & 68 & 72 & 77 & 72.5 & 75 \\
\hline ID18 & $67^{*}$ & 72 & 72 & 72 & 73 & $69^{*}$ & 76 & 73.1 & 76 & 70.5 & 75.5 \\
\hline ID19 & 71 & 74 & 74 & 74.5 & $65.5^{*}$ & 74 & $66.5^{*}$ & 71.5 & 77 & 72.5 & 77 \\
\hline ID20 & 71 & 74 & 74 & 74 & 72.5 & 84 & 77 & 70 & 77.5 & 70 & 77.5 \\
\hline ID21 & 72 & 76.5 & 76 & 76 & 72 & 82 & 77 & $69^{*}$ & 77 & 70 & 77 \\
\hline Total & 70.6 & 73.2 & 74.6 & 75 & 74.1 & 75.8 & 75.2 & 71.6 & 76 & 73.3 & 77.6 \\
\hline
\end{tabular}

The above Table shows that, PLOs (by the direct methods of assessment) achieved the target value (70 \%), where PLOs rated between (70.6\%) and (77.6\%). PLO11 achieved the highest value compared to the other PLOs, where it rated (77.6 \%). While PL01 achieved the lowest value, where it recorded (70.6\%).

The comparison between the results of PLOs assessment by direct and indirect methods are displayed in Figure 1.

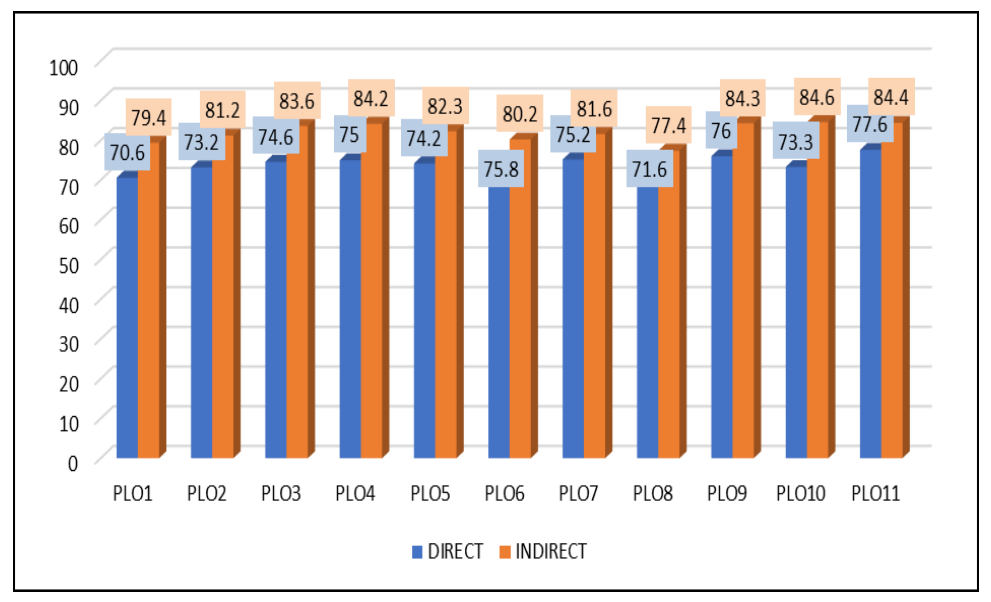

Figure 1 Comparison between the results of PLOs achievement by direct and indirect methods

It is clear from the above Figure, all PLOs achievement by indirect methods recorded higher values than that by direct methods. The collected results by surveys (the indirect method) displayed that, the students give a feedback within rate 3.87 and 4.23 out of $5 ;(77.4 \%$ and $84.6 \%)$.

Also, the measurements of PLOs by the indirect methods showed that, they achieved the target benchmark (80\%) except PL01 and PL08, where they rated (79.4\%) and (77.4\%) respectively.

PL011 recorded the highest value of students' achievement by using the indirect methods, where it rated (84.6 \%). While PL08 rated the lowest value of student's achievement (77.4\%) by indirect method. 


\section{Conclusion}

Overall, direct and indirect assessment methods carried out to assess the PLOs of radiological sciences graduating students, have been successfully implemented. Results show that the indirect assessment methods rated higher values than the direct assessment for all PLOs.

PL011 (Demonstrate teamwork and inter-professional collaboration) recorded similar achievement approach by using the both assessment methods, where it achieved the highest values compared to the other PLOs.

The difference between the mean value of the students' achievement of PLOs by using the indirect and direct assessment methods equals $3.8 \%$.

According to the obtained results, continuous quality improvement was suggested and carried out. Course report and annual program report are prepared, including the achievement of students' learning outcomes in radiological sciences program at Najran University. Finally, these reports contain feedback and recommendations from the courses coordinators to improve the student's achievement for next semester.

In general, the applied method is able to measure the achievement of PLOs and it supported by an indirect assessment method. The radiological sciences program highlights on the student outcomes for the graduate for continuous quality of the curriculum and teaching and learning process in future.

\section{Compliance with ethical standards}

\section{Acknowledgments}

The authors would like to express their gratitude to the Ministry of Education and the Deanship of Scientific Research, Najran University, Kingdom of Saudi Arabia for their financial and technical support.

\section{Disclosure of conflict of interest}

Author hereby state that there is no conflict of interest.

\section{Statement of ethical approval}

After approval of the research proposal by the deanship of scientific research, it was reviewed by Najran University ethical review panel. A formal approval to carry out the study was obtained from the Dean of Applied Medical Sciences College to conduct the study after an explanation of its objectives. Informed consent was taken from each student. All data was confidential and used for the research purpose only.

\section{Statement of informed consent}

Informed consent was obtained from all individual participants included in the study.

\section{References}

[1] Al-Shammari, Z. Assessment of student learning outcomes of indicators of strengths and weaknesses, 4th International Conference of Education, Research and Innovation. At: Madrid, Spain. 2011.

[2] 1-Jodin Makinda et al. Assessing the Achievement of Program Outcome on Environment and Sustainability: A Case Study in Engineering Education, 2nd Regional Conference on Campus Sustainability: Capacity Building in Enhancing Campus Sustainability. University Malaysia Sabah, Kota Kinabalu, Malaysia. 7th - 8th. 2015.

[3] Tucker B. Literature Review: Outcomes-focused Education in Universities. Learning Support Network, Cambridge University. Retrieved 19 October 2004.

[4] Spady W. Organizing for results: the basis of authentic restructuring and reform. Educational Leadership. 1988; 46(2): 4-8.

[5] Spady W. Outcome-based Education. Belconnen, ACT: Australian Curriculum Studies Association. 1993. 
[6] R Eldeeb, N Shatakumari. Outcome Based Education (OBE) - Trend Review, IOSR Journal of Research \& Method in Education (IOSR-JRME), 2003; 1(2): 09-11.

[7] Crespo RM, Najjar J, Derntl M, Leony D. Neumann S, Oberhuemer P, Totschnig M, Simon B, Gutierrez I, Kloos CD. Aligning assessment with learning outcomes in outcome-based education. IEE Education Engineering. Madrid Spain. 2010; 1239-1246.

[8] Biggs JB, Tang CS. Teaching for quality learning at university: What the student does, e-Book 3rd edition, McGrawHill. 2007.

[9] Blanford D, Hwang D. Five easy but effective assessment methods. SIGCSE'03 Proceedings of the 34th SIGCSE technical symposium on Computer science education. 2003; 35: 41-44.

[10] Soroor kH. Al-khafaji et al. Assessment of learning outcomes to educational objectives of mechanical engineering department /Baghdad University, The Second International Arab Conference on Quality Assurance in Higher Education. 2012.

[11] Hutchings P. What new faculty need to know about assessment. Champaign, IL: National Institute for Learning Outcomes Assessment. 2011.

[12] ABET Engineering Accreditation Commission, Criteria for Accrediting Engineering Programs. 2012-2013.

[13] Mirna Nachouki. Assessing and Evaluating Learning Outcomes of the Information Systems Program, World Journal of Educational Research, 2017; 4(4).

[14] Mehdi R, Abou Naaj M. Academic Program Assessment: A Case Study of a Pragmatic Approach. Creative Education Journal. 2013; 4(1): 71-81.

[15] Norliza Abd.Rahman et al, Assessment Tool of Course Learning Outcomes for Mechanical Design of Process Equipment, 6th International Forum on Engineering Education (IFEE 2012), Procedia - Social and Behavioral Sciences. 2013; 102: 116 - 121.

[16] Sudheer K, Sujit VVN, Prasad NVG, Ravichand K. A novel method of learning outcome assessment in outcomebased education. In 4th International Conference IEEE on MOOCs, Innovation and Technology in Education (MITE), 9 December 2016; 328-331.

[17] Erdenekhuu Norinpel et al. Assessment experience on program learning outcomes, Proceedings of the 14th International CDIO Conference, Kanazawa Institute of Technology, Kanazawa, Japan. 2018.

[18] Soheir E. Mohamed. Samia A. fathelrahman. Study on different assessment methods for students' achievement in applied medical sciences at Najran University, SYLWAN. 165(1), 2021; 113-125. 